\title{
047
}

\section{UN RARO CASO DI MENINGITE DA NEISSERIA MENIGITIDIS DI GRUPPO A}

Podda R'.,Podda R. ${ }^{2}$ Porcu P.P'., Sanna M.'

'Ospedale Oncologico "A.Businco" - Cagliari

${ }^{2}$ Ospedale Regionale per le Microcitemie - Cagliari

Nel mese di maggio è stato ricoverato presso il reparto di Pediatria un bambino di 3 anni, con possibile richetziosi da puntura di zecca. Il bambino, che aveva trascorso i giorni precedenti in campagna, presentava da 48 ore iperpiressia intermittente $\left(39-40^{\circ} \mathrm{C}\right)$, prevalentemente nelle ore notturne, con esantema maculare diffuso che si accentuava durante $\mathrm{i}$ rialzi febbrili.

Al momento del ricovero mostrava irritabilità, febbre continua, rigidità nucale. Si sospettò una meningite. Venne intrapresa una terapia iniziale con vancomicina (sospesa per allergia) e Ceftriaxone (100 mg/Kg/die) per 12 giorni.

Furono richiesti i seguenti esami: emocromocitometrico (GB 26.200, neutrofili $81 \%$, linfociti $10.4 \%$, monociti $7 \%$, GR 4.500.000, PLT 314.000), VES (prima ora 89), PCR (14 $\mathrm{mg} / \mathrm{dl}$ ), PT, PTT e fibrinogeno, imunoglobuline sieriche e LDH (tutti compresi negli ambiti di riferimento) e la sierodiagnosi di W-F che risultò negativa.

IL Liquor appariva biancastro e sensibilmente torbido; la glucorrachia era di $45 \mathrm{mg} / \mathrm{dl}$, la protidorrachia di $214 \mathrm{mg} / \mathrm{dl}$ e i cloruri $123 \mathrm{mEq} / \mathrm{l}$. La conta delle cellule era di 900 elementi figurati $/ \mathrm{mm}^{3}$.

Venne effettuata la semina del Liquor sia aerobiosi che $\mathrm{CO}_{2}$. Il Gram, il blue di metilene e l'inchiostro di china non evidenziarono nulla di particolare. Negativa la ricerca antigenica diretta di Neisseriae, Haemophilus e Pneumococchi.

Dopo 24 ore, le piastre incubate in aerobiosi non evidenziarono alcuna crescita, mentre erano presenti su Agar cioccolato incubato in $\mathrm{CO}_{2}$ delle piccole colonie grigiastre che vennero identificate (mini API bioMerieux) come Neisseria meningitidis. La tipizzazione sierologica individuò il sierotipo di gruppo A.

Gli esami si normalizzarono dopo $10 \mathrm{gg}$.

In Italia i sierotipi di Neisseria meningitidis più frequenti sono il tipo B ed il C, rari i sierotipi W-135, X, Z1, Y, ed A. Quest'ultimo è frequente con un'incidenza elevatissima nella cosiddetta cintura sahariana. Dato l'elevato numero di immigrati provenienti da tali zone, che popolano attualmente la Sardegna è probabile che l'infezione di cui sopra sia stata contratta dal contatto con qualcuno di questi soggetti portatore sano della Neisseria meningitidis. 